\title{
Effect of Body Mass Index on the Level Development of Early Childhood Locomotors Capabilities in Children Aged 5 to 6 Years
}

\author{
Zainul Johor, Muhammad Rizky Mezra*, Khairuddin, Nirwandi, Oktarifaldi, Irfan Oktavianus, Syahrial Bakhtiar \\ Faculty of Sport Science \\ Padang State University \\ Padang, Indonesia \\ *rizkymezra9@gmail.com
}

\begin{abstract}
This study aims to look at the effect of Body Mass Index on the level of development of children's locomotor abilities. The population in this study were all students in Early Childhood Education aged 5 to 6 years in Padang Pariaman Regency. A random sampling technique chooses the sample with the total sample is $\mathbf{4 2}$ children. The instrument used to obtain data on the Body Mass Index of children aged 5 to 6 years is to perform anthropometric tests measuring height and weight. In contrast, the locomotor ability of the child is obtained by using the Test of Gross Motor Development-2 (TGMD-2). Based on the results of the research conducted, there is the influence of Body Mass Index on the level of development of children's locomotors abilities with a value of $r$ count $0.426>r$ table 0.304 and a significant value $(\mathrm{Sig})$ of 0.005 is smaller than the probability of $\mathbf{0 . 0 5}$. The results of this study indicate that their Body Mass Index influences the level development of locomotors abilities possessed by the children from age 5 to 6 years old in Padang Pariaman Regency.
\end{abstract}

Keywords - Body Mass Index, Locomotor Ability Level

\section{INTRODUCTION}

Early childhood is the most important and basic early period throughout the range of growth and development of human life. This period is marked by various important periods that are fundamental in the child's life until the end of the development period. One period that characterizes early childhood is the golden period. Many of the concepts and facts found provide an explanation of the golden period at an early age, in which it is the time when all the potentials of a child develop the fastest. Some concepts that are juxtaposed for early childhood are the exploration period, the identification / imitation period, the sensitive period, the play period, and the period of defiance of the early stages. However, early childhood is a critical period in which the child's golden period will not be repeated in subsequent periods, if the potential is not optimally stimulated at that early age. The impact of not stimulating the various potential at the golden age, will hinder the next stage of child development. So, the golden age only occurs once in life of the children and it cannot be repeated anymore.

It is very disadvantage if a family or community ignores the program that has been set by the government, namely Early Childhood Education (PAUD) which is actually listed in Chapter I article 1, paragraph 14, which emphasizes that
Early Childhood Education is a coaching effort aimed at children from birth up to the age of six years through the provision of educational stimuli to help physical and spiritual growth and development so that children have suc of the readiness to enter further education (USPN Depdiknas, 2004: 4) [1]. Early childhood education is the most appropriate in developing physical-motoric, cognitive, social-emotional, linguistic, moral and religious aspects. Realizing the positive benefits for the development of their children, the community or families in Indonesia began to be interested in this Early Childhood Education program. Triggered by their interest, this program develops rapidly. This PAUD program includes POSPAUD, Child Care Center (TPA), Play Group $(\mathrm{KB})$, and Kindergarten (TK).

The basic ability of movement is the basic ability for children to do the next level of movement, whether it is an organized movement or not organized [2]. These skills allow children to control their bodies, manipulate their environment and display complex skills and developmental patterns involved in sports and other recreational activities [3].

Motor skills and balance are part of the prerequisites for physical function and sports performance (Venetsanou, 2011, , 2011) [4]. Most motor skills are acquired by children during the preschool period. Motor skills and balance are also the basis of physical developmental milestones in children. These skills are further polished for more complex movements such as running, jumping, and sports activities. Any disturbance in motor skills and balance can increase the risk of falls and injury even in healthy children during participating sports activities.

At the age of 2 to 7 years old is a golden period of child development (basic development phase of the movement). This age will allow children to interact with their environment so that their basic physical abilities can be further developed and learn new abilities to move on the next level [5]. The basic ability of movement possessed by a child is influenced by several factors, such as internal and external factors. Internal factors consist of biological, psychological, social, motor, and cognitive. Furthermore, external factors consist of the environment, opportunities to participate in physical activities, encouragement and teaching. Motivation and stimullation provided by the environment is considered 
as the most important factor because it allows children to move from the initial stage to the adult stage in mastering movement skills [5].

In another study, it was also explained that the motor ability and the balance of a child are influenced by several factors, for example children who are more physically active and have a normal body mass will commonly have a better balance compared to the children who rarely do physical activity and have a larger body [6].

Body Mass Index (BMI) also has an influence on a child's motor skills. Body Mass Index (BMI) is a measure used to assess the proportionality of a person's height and weight. Body Mass Index is often used by doctors to judge whether someone is obese or not. Body Mass Index (BMI) is a technique for calculating body weight index, so we can know the category of our body whether classified as thin, normal and obese (overweight). Body Mass index is a calculation of height and weight for all children [7]. Based on his research findings that BMI has a correlation of all objects for basic mobility.

According to some of the expert opinions above, it can be concluded that balance is a basic ability that must be possessed by a child during the stages of motor development and development which is the basis for making more complex movements. At this stage, the children's motor skills are declining because children are lack of opportunities to develop the abilities they have.

\section{LEVEL DEVELOPMENT OF LOCOMOTOR ABILITY AND BODY MASS INDEX}

\section{A. Level of Locomotor Capability Development}

Locomotors capabilities allow individuals to move from one room or move from one point to another and form the basic ability for something related to sports, games, and life-long activities. The Locomotors capability consists of a group of FMS that allows individuals to determine through their place or body movement from one point to another.

The development of basic competencies in locomotors abilities is important in the involvement of physical activities that are useful for health and for moving effectively in various sports, games and dance. Running, galloping, hopping, skipping, jumping, leaping, and sliding are the most common forms of locomotors capability.

\section{Run}

Running is a form of movement that directs the body forward with intermittent legs as the base support. Factors such as contralateral patterns, strength to weight ratio, and dynamic balance are all important in developing running skills. Running is the earliest stage of FMS around 18-22 months with girls a little slower than boys. Boys go through this stage faster and reach the advanced stage of running at the age of 4 years. For women, only a few can be proficient at the age of 5, which can be seen at stage 4 .

\section{Gallop and Slide}

Galoping and sliding are very similar movements. Both require rhythmic movements to step forward along with the jumps to the other foot. The gait of this pattern is asymmetrical and uneven. Galloping appeared first and it was the first asymmetric locomotors ability learned by children. Galloping leads forward while sliding leads sideways. To do galloping and sliding, children need dynamic balance, coordination and the child's strength toward the weight ratio which can affect the aspects of the movement.

Galloping is a skill gained from a combination of stepping and jumping with irregular temporal components. Beginner gallopers struggle with many aspects of galloping skills and in the initial stages they look like they are running in a sloping manner. Beginner gallopers who have a favourite foot position cannot gallop with their feet in front. Beginner gallopers (stage 1) resemble running with different rhythms. The limb is dragged in front of the first leg while in the air. The front foot remains the first to touch the floor. In stages one and two there might be a tendency to increase the ability. In Professional stage (stage 3), there is an increase in the components of the skill.

\section{Skip}

Skipping consists of a combination of movements that makes the child jump with the front foot of the chart first, followed by the back foot. Like other locomotors skills, this skill can be influenced by the child's body weight ratio and this is a fact for skipping where weight is projected onto the floor on one foot. A professional skipper displays easy and unchanging movements and is close to the floor. They have enough dynamic balance and leg strength in each leg to show the smooth hopping movements on each leg. So hoping in stage 3 is the basic movement in hopping to be developed.

\section{Jump}

Jumping is the ability of the body that involves both feet in landing and take off skills. Jumping is assessed from 2 components, namely the feet and hands. Changes in the movement of body components is a product that is an aspect of assessment in skill jumping, namely the feet and hands. It takes a long time to develop to the professional stage from the initial stage.

\section{Hop}

Hopping is the ability of locomotives to estimate the body when jumping and landing with the same foot. There are four stages of Hopping, one of the conclusions to distinguish between the four stages of Hopping is the position of the free-swinging legs and feet. At the beginning stage, (stage 1) the swing legs are in front of the converter's feet, and the thighs are in a horizontal 
position to provide a strong balance. The advanced hopper began to lower the swinging leg along with the foot of the converter with the thigh at a 45-degree angle to the pelvis (stage 2). The arms are used bilaterally. At level 3, the swing legs are behind the converter's feet and the thighs are parallel to the feet on the extended hopper. As explained above, in stage 4, hopper uses swing legs to generate energy and pumps swinging feet in swinging motion. Hoppers in both phases show better balance, leg strength and better body coordination.

Each skill in locomotors ability is given an assessment based on the development sheet of the child's locomotors ability level [9]. The assessment will be based on a video recording of locomotors abilities displayed and coded according to the level of development of each child's locomotors ability. Students sampled in the study were those at the age 5 to 6 years old. There are several tools used to support this research, including meter (1), traffic cone (2) and camera (3).

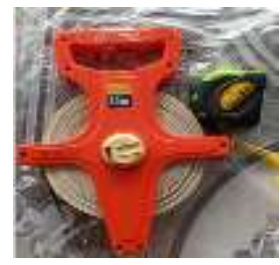

Picture 1. Meter

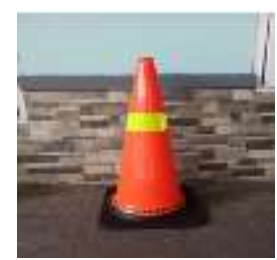

Picture 2. Traffic cone

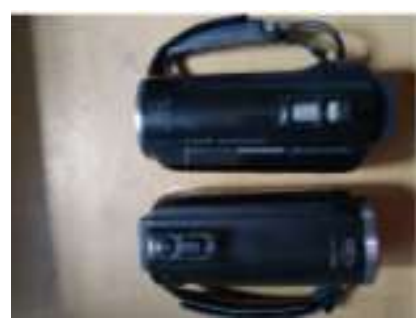

Picture 3. Camera

\section{B. Body Mass Index}

Body Mass Index (BMI) is introduced as an important component of holistic growth assessment. BMI is a score that is calculated as the ratio of an individual's weight in kilograms to height in meters squared $\left(\mathrm{kg} / \mathrm{m}^{2}\right)$ [8]. In children, the BMI score is adjusted for age and sex to account for changes in growth and body fat that occur as part of normal development. Infants and young children have a relatively higher proportion of fat as a component of normal growth.
BMI data is obtained by measuring students' height and weight. Student body height is measured using a meter in $\mathrm{cm}$. The measured student body height is then written into the sheet provided. While the weight is weighed using a digital scale that is able to record a student's weight up to 2 digits behind the comma.
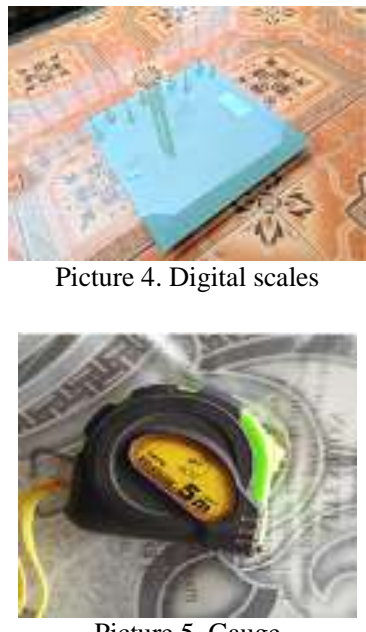

Picture 5. Gauge

\section{The DATA ACQUisition SetUP}

The instrument used to obtain data on BMI of Early Childhood Education students was height and weight measurements while the level of locomotors ability of children was obtained based on the INDO-SKIP Training sheet [9]. Then for the child's equilibrium data obtained with 1 trial for each movement and this data is stored in the form of a test sheet. This test is given to children aged 5 to 6 years. Sample withdrawal technique uses the purposive sampling technique in which the sample is chosen by taking a lot of certain considerations [10]. The number of students involved was 42 consisting of 24 women and 18 men.

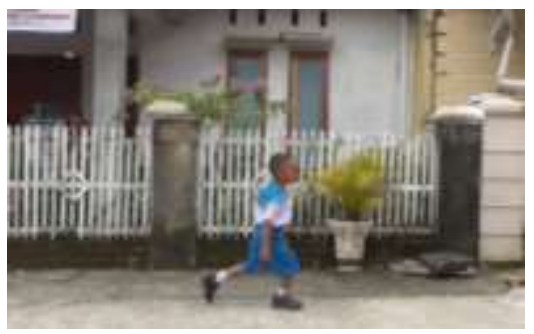

Picture 6. Illustration of galloping

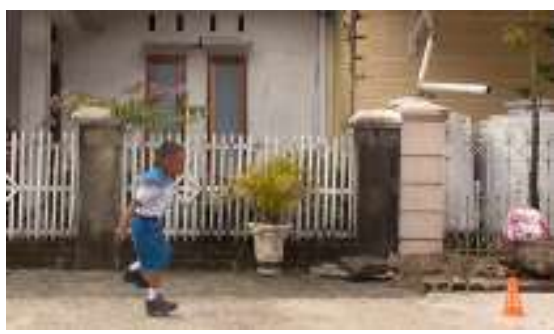

Picture 7. Illustration of hopping 


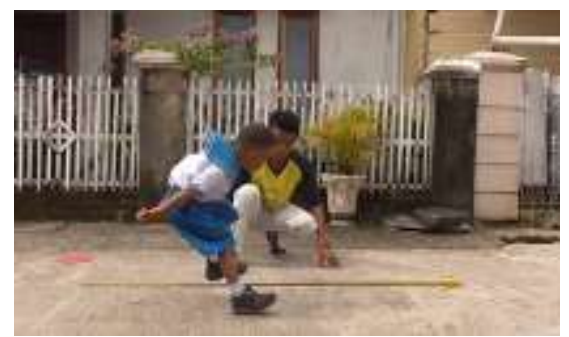

Picture 8. Illustration of jumping

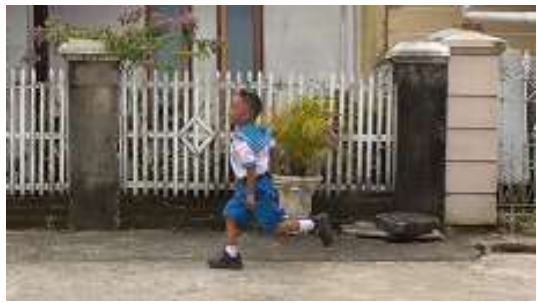

Picture 9. Illustration of running

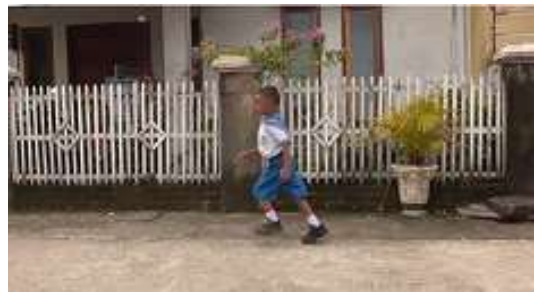

Picture 10. Illustration of skipping

\section{THE DATASET}

Data on the level of development of Early Childhood Education students' locomotors abilities in Kabupaten Padang Pariaman were taken 2 times for all children for each skill tested. Data from the test is stored in video format. The grading of the level of development of this locomotors ability is based on the INDO-SKIP Training sheet. Furthermore, BMI data is obtained by measuring the height of the body using the meter and weight with the help of digital scales, the use of digital scales is considered to be able to provide an accurate calculation of the weight being weighed. This test is given to children at the age of 5 to 6 years. The number of students involved was 42 consisting of 24 girls and 18 boys.

\section{CONCLUSIONS}

This study involved 42 PAUD students aged 5 to 6 years. It is recommended for parents and teachers to educate children and to pay attention to the BMI they have. BMI that is lacking or excessive will not only trigger a lot of diseases such as obesity or malnutrition but can also inhibit the growth and development of children's basic mobility, especially locomotors abilities. In the future, it is expected that there will be more similar research models that examine the children's locomotors ability and factors that also influence the sample in a larger area.

\section{REFERENCES}

[1] Depdiknas. "Kurikulum Taman kanak-kanak (TK) dan Raudhatul Athfal (RA)". Jakarta: Direktorat Jenderal Jendidikan Dasar dan Menengah. 2004.pp.10-16.

[2] Nagoor Meera Abdullah \& Vincent Parnabas. "Assessing Gross Motor Skills Development Among Children with Visual Impairment". International Journal of Education and Research Vol. 2 No. 2 February 2014. ISSN: 2201-6333 (Print) ISSN: 2201-6740

[3] Haywood, K. N. Getchell, "Life Span Motor Development, 3rd ed., Champaign": Human Kinetics,2001.pp.12-18.

[4] Mickle et al. "Geologic and hydrologic control of porewater chemistry and submarine groundwater discharge into Indian River Bay, Delaware". Goldschmidt 2011 conference, Prague, Czech Republic, August 14-19. p. 1462

[5] Aggeliki Tsapakidou, Theofilaktos Anastasiadis, Despoina Zikopoulou\& Eleni Tsompanaki. "Children Coming from Two Areas of Thessaloniki with Contrasting Socioeconomic Status". Asian Journal of Humanities and Social Studies (ISSN: 2321-2799) Volume 02 - Issue 01, February 2014.

[6] Wrotniak BH, Epstein LH, Dorn JM, Jones KE, Kondilis VA. "The relationship between motor proficiency and physical activity in children". US National Library of Medicine National Institutes of Health Pediatrics". 2006 Dec;118(6):e1758-65.

[7] Marefat Siahkouhian, Hiva Mahmoodi and Masoud Salehi. "Relationship Between Fundamental Movement Skills and Body Mass Index in 7-To-8 Year-Old Children". World Applied Sciences Journal 15 (9): 1354-1360, 2011. ISSN 1818-4952 (C) IDOSI Publications, 2011.

[8] Melissa Wake \& Brigit Maguire. Children's body mass index Cohort, age and socio-economic influences. LSAC Annual Statistical Report. 2011.pp.10-14

[9] Famelia, Ruri., Goodway, Jacqueline D \& Bakhtiar, Syahrial. "INDOSKIP Training". The OHIO State University. 2017.pp.23-35.

[10] Sugiyono. "Metode Penelitian Kuantitatif, Kualitatif dan R\&D. Bandung: PT Alfabeta. 2016.pp.12-34. 